\title{
STRESS AMONG NURSES FROM COUNTRIES VARIOUSLY AFFECTED BY THE COVID-19 PANDEMIC - RESULTS COLLECTED IN POLAND AND IRAN
}

\author{
Andrzej Piotrowski ${ }^{1}$, Zahra Nikkhah-Farkhani ${ }^{2}$, Ryszard Makarowski ${ }^{3}$ \\ ${ }^{1}$ University of Gdańsk, Gdańsk, Polska \\ Institute of Psychology \\ ${ }^{2}$ University of Bojnord, Bojnord, Iran \\ Business Management Department \\ ${ }^{3}$ The Elblag University of the Humanities and Economics, Elblag, Poland \\ Faculty of Health Sciences
}

\begin{abstract}
Background: Nursing involves numerous stressful situations, such as overwork, night shifts, responsibility for the patients' health, rapid pace of work, emotional demands, contact with suffering individuals, and patients' aggressive behaviors. The SARS-CoV-2 pandemic is an additional demand on the already demanding profession. Thus, the aim of the current study was to assess the character of the relationship between overwork and subjectively experienced stress, taking into account the moderating role of contact with patients and work in facilities dedicated for COVID-19 patients, and the strategies of coping with stress, including resilience, in countries affected by the pandemic to various degrees. Material and Methods: The study was carried out on 151 Iranian and 158 Polish nurses at the beginning of June 2020. The following research tools were used: the Overwork Climate Scale, the Brief COPE, the Resilience Scale, and the Perception of Stress Questionnaire. The participants were also asked about their contacts with patients infected with COVID-19, and work in facilities dedicated for such patients. Results: Polish and Iranian nurses reported similar levels of overwork, but they differed with respect to the level of subjectively experienced stress and they used different coping strategies to various degrees. Contact with patients infected with COVID-19 and work in facilities dedicated for such patients also moderated the relationship between overwork climate and resilience. Conclusions: Stress levels among Iranian and Polish nurses during the pandemic are different and are related to the intensity of contact with patients infected with COVID-19. Culture and context have an important impact on coping strategies which requires further studies with a multinational approach. 2021;72(5):457-65
\end{abstract}

Key words: coping strategies, resilience, general nurse, sense of stress, overwork, COVID-19

Corresponding author: Andrzej Piotrowski, University of Gdańsk, Institute of Psychology, Jana Bażyńskiego 4, 80-309 Gdańsk, Poland, e-mail: andrzej.piotrowski@ug.edu.pl

Received: February 8, 2021, accepted: May 26, 2021

\section{INTRODUCTION}

Nurses are a key part of the healthcare sector and they constitute the largest group among healthcare workers. From over 43.5 million healthcare workers globally, nearly $50 \%$ are nurses and midwives [1]. Nurses play an important role in healthcare teams - they are frontline workers who come into contact with a wide variety of patients. Thus, they face high occupational risk [2].

Due to the nature of their work - providing the best possible care for patients - nurses and midwives not only work multiple shifts (including night shifts), but also extended shifts, up to $12 \mathrm{~h}$ (compared with the standard $8 \mathrm{~h}$ ), which negatively impacts on their health. Working overtime is common among nurses [1].

Nurses' daily work in hospitals is by nature difficult, stressful, and highly complex. It involves numerous very stressful situations and challenges, such as heavy workloads, shift work, emotional challenges, and occupational conflicts. Nurses experience workplace stress from many sources, especially in the context of the hospital environment, which changes rapidly in response to developments in medical technology [3]. This is due to their constant engagement in highly emotionally demanding relationships with subordinates, as well as intense cognitive and quantitative demands. The lack of adequate healthcare resources, together with an increase in the proportion of elderly patients in the population, have caused a greater quantitative demand for nurses, especially in the context of rising demands, workload, and pace of work [4]. Workplace stress among nurses is closely related to their workplace conditions and atmosphere [5]. A high degree of overwork among nurses results in workplace stress, which can lead to burnout. 
The increasing number of patients requiring care results in chronic fatigue among nurses [6].

Both Polish and Iranian nurses are faced with much greater workloads during the pandemic compared to how it was before. Additionally, in Iran, a much smaller proportion of nurses per 1000 citizens had to struggle with much higher patient numbers. Aside from more work, this also involves greater health risks for the medical personnel due to the possibility of contracting the infection. Moreover, work during the pandemic requires the use of personal protective equipment (PPE), which reduces the risk of infection, but also makes regular work much more difficult to carry out. At the beginning of the pandemic, Iranian nurses had much less access to PPE compared to Polish nurses.

The severe acute respiratory syndrome coronavirus 2 (SARS-CoV-2) has spread throughout the world at an unprecedented rate. The epidemic began in China at the end of 2019, and by May 2020 over 3 million infections had been reported worldwide [7]. Frequent asymptomatic cases, the lack of precise tests, and a high risk of transmission caused the infections to spread rapidly and made establishing the precise number of infected people impossible. As of April 2020, half of the infected patients in Iran and Poland were healthcare workers.

The COVID-19 pandemic has severely strained healthcare systems all over the world. Reports of insufficient resources to provide safe care for patients can be heard daily. One issue is the lack of adequate PPE and tests, which causes frontline nurses to experience additional stress. Concern, alleviation of suffering, fostering the return to good health, and respect for the rights and dignity of each patient are the fundamentals of nursing. However, during the COVID-19 pandemic, nurses are forced to balance the demands of caring for patients with caring for themselves and their families. These conflicting demands can cause additional strain in the conditions which were already highly stressful [8]. According to Godlee [9], healthcare workers and social workers are dying due to the occupational risk of the COVID-19 infection.

Nurses, who are often overworked and under intense workplace stress under regular conditions, face additional strain during the COVID-19 pandemic. Overwork refers to the conduct of those employees that dedicate an amount of time to their work so excessive that it begins to entail escalating risks beyond those associated with agreed-upon standard hours [10]. Organizations expect their employees to commit extra hours to work, which allows them to realize a large number of tasks without the need of employing additional personnel [11]. An increased number of patients requiring urgent care, a high risk of infection, insufficient PPE, imprecise tests, and high infection rates among medical personnel are some of the challenges they have to face [12]. Nurses understand the necessity of accepting a greater workload during the pandemic.

Personal resources, including resilience, play an important part in coping with stress [13]. Resilience is a dynamic process, in which 2 phenomena can be distinguished. The first involves the individual facing a risk of a certain negative life situation, which causes difficulties in adaptation. The second involves displays of positive adaptation, evident in gaining competences, realizing developmental goals, and not developing emotional or behavioral disorders. Individuals with high resilience are productive and goal-oriented. They display emotional stability and a sense of humor, and they perceive stressful events mainly as challenges. They also complete the plans they have begun. Psychological resilience might thus protect nurses from the negative consequences of stress.

Carver [14] distinguished 14 strategies of coping with stress, which can be grouped into 3 categories: emotion-focused strategies, problem-focused strategies, and dysfunctional coping strategies [15]. Another categorization involves adaptive and maladaptive coping strategies [16], or seeking social support, problem solving, avoidance, and positive thinking [17]. Regardless of the adopted categorization, preferring certain coping strategies might be related to heightening or lowering subjectively experienced stress. Research by Jeong et al. [18] showed that adaptive coping strategies, together with resilience, lower experienced stress among nurses.

Iran and Poland differ in many aspects. The population of Iran is 81 million, while the population of Poland is 38 million. Iran is a young society - the mean age is 32.2. In comparison, the mean age in Poland is 40.2. Though Poland is a demographically smaller country, it has more nurses and midwives - around $258000 \mathrm{com}$ pared to Iran's 160 000, which translates into 1.5 nurses per thousand citizens in Iran and 5.2 per thousand citizens in Poland. The 2 countries also differ in terms of the dynamics of progress of the COVID-19 pandemic. At the time of data collection in the current study (the beginning of June 2020), Iran had 170000 confirmed infections, while in Poland this number was under 1200. 


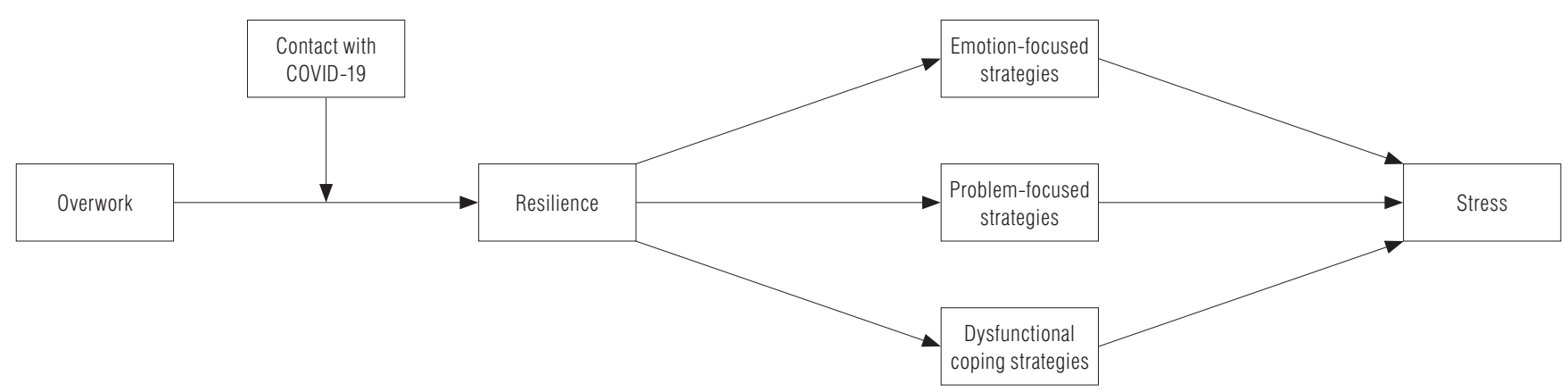

Figure 1. The conceptual model addressing the relationships between overwork, contact with COVID-19, resilience, coping strategies, and stress

On the basis of these considerations, a study of nurses during the COVID-19 pandemic was designed and a hypothetical model of relationships between workplace experiences and perceived stress in countries variously affected by the COVID-19 pandemic was created (Figure 1).

The following research questions, relevant to the research objective, were formulated:

- Do Polish and Iranian nurses differ in terms of stress levels?

Do nurses who have contact with patients infected with COVID-19 and nurses who do not have such contact differ in terms of stress levels?

Does contact with patients infected with COVID-19 modify the relationship between overwork and resilience?

Do Polish and Iranian nurses differ in terms of overwork, resilience, coping strategies, and the degree of contact with COVID-19 patients?

Do nurses who have contact with patients infected with COVID-19 and nurses who do not have such contact differ in terms of overwork, resilience, coping strategies, and the degree of contact with COVID-19 patients?

\section{MATERIAL AND METHODS}

\section{Participants}

Polish $(\mathrm{N}=158,144$ female $)$ and Iranian $(\mathrm{N}=151$, 90 female) nurses took part in the study. The Polish nurses' mean age was $34.92(\mathrm{SD}=6.65, \mathrm{~min} .=20$, $\max =43)$; 13 nurses had secondary education, 83 had BA degrees, and 62 had MA degrees. The Iranian nurses' mean age was $28.34(\mathrm{SD}=5.56, \min .=22, \max =$ 49); 12 nurses had secondary education, 103 had BA degrees, and 36 had MA degrees. Iranian nurses were younger than Polish nurses, which follows the general demographic trends of these countries. Of note is also the large proportion of men in the Iranian sample. Four methods were used to measure the variables included in the study.

\section{Overwork Climate Scale}

The Overwork Climate Scale by Mazzetti et al. [10] measures the subjective perception of a climate of overwork at one's place of employment. It consists of 11 items forming 2 subscales: Overwork Endorsement (7 items, e.g., "It is considered normal to work on weekends") and Lacking Overwork Rewards (4 items, e.g., "Working overtime is fairly compensated financially"). The respondents were asked to rate their agreement with each item on a 5-point Likert scale (1 - "I strongly disagree," 5 - "I strongly agree"). The mean of the subscale scores forms the total score. The higher the score, the more pronounced the overwork climate.

\section{Coping with stress}

The Brief COPE by Carver [14] is a popular questionnaire measuring 14 strategies of coping with stress (each strategy being measured by 2 items) [14]. These are: self-distraction, active coping, denial, substance use, use of emotional support, use of instrumental support, behavioral disengagement, venting, positive reframing, planning, humor, acceptance, religion, and self-blame. The respondents were asked to indicate how often they engaged in each behavior described by the items on a 4-point Likert scale (1 - "I haven't been doing this at all", 4 - "I've been doing this a lot"). The higher the score on a given scale, the more often a given strategy is preferred when coping with stress.

\section{Resilience}

To measure resilience, the Resilience Scale by Ogińska-Bulik and Juczyński [19] was used. It consists of 25 items, 
Table 1. Descriptive statistics of the analyzed variables among Iranian and Polish nurses in state-owned hospitals at the beginning of June 2020

\begin{tabular}{|c|c|c|c|c|c|c|c|c|c|c|}
\hline \multirow{4}{*}{ Variable } & \multicolumn{10}{|c|}{$\begin{array}{c}\text { Participants } \\
(\mathrm{N}=309)\end{array}$} \\
\hline & \multirow{2}{*}{\multicolumn{2}{|c|}{$\begin{array}{c}\text { Iranian } \\
(\mathrm{N}=151)\end{array}$}} & \multirow{2}{*}{\multicolumn{2}{|c|}{$\begin{array}{c}\text { Polish } \\
(\mathrm{N}=158)\end{array}$}} & \multicolumn{4}{|c|}{ contact with COVID-19 } & \multirow{2}{*}{\multicolumn{2}{|c|}{ total }} \\
\hline & & & & & \multicolumn{2}{|c|}{$\begin{array}{c}\text { yes } \\
(\mathrm{N}=40)\end{array}$} & \multicolumn{2}{|c|}{$\begin{array}{c}\text { no } \\
(\mathrm{N}=269)\end{array}$} & & \\
\hline & $\mathrm{M}$ & SD & $\mathrm{M}$ & SD & M & SD & $\mathrm{M}$ & SD & $\mathrm{M}$ & SD \\
\hline Overwork & 3.06 & 0.39 & 2.84 & 0.38 & 3.06 & 0.38 & 2.84 & 0.41 & 3.03 & 0.42 \\
\hline Reliance & 3.65 & 0.55 & 3.68 & 0.53 & 3.68 & 0.53 & 3.65 & 0.60 & 3.65 & 0.59 \\
\hline Emotion-focused strategies & 2.93 & 0.41 & 2.76 & 0.50 & 2.76 & 0.50 & 2.73 & 0.45 & 2.73 & 0.45 \\
\hline Problem-focused strategies & 3.15 & 0.47 & 3.17 & 0.57 & 3.17 & 0.57 & 3.02 & 0.43 & 3.04 & 0.45 \\
\hline Dysfunctional coping strategies & 2.32 & 0.35 & 2.33 & 0.32 & 2.33 & 0.32 & 2.21 & 0.38 & 2.23 & 0.38 \\
\hline Stress & 3.04 & 0.65 & 2.93 & 0.64 & 3.24 & 0.64 & 2.93 & 0.76 & 3.20 & 0.75 \\
\hline Contact with COVID-19 & 1.58 & 0.41 & 1.84 & 0.26 & - & - & - & - & 1.71 & 0.36 \\
\hline
\end{tabular}

arranged into 5 subscales (5 items for each subscale): Perseverance and Determination (e.g., "I try to overcome challenges regardless of how difficult they are"), Openness to New Experiences and Sense of Humor (e.g., "I can see the funny side of the situations which I have to deal with"), Personal Coping Competences and Tolerance of Negative Emotions (e.g., "I can adjust to all situations, even the most difficult ones"); Tolerating Failures and Treating Life as a Challenge (e.g." "I easily adapt to new situations"), and Optimistic Attitude to Life and the Ability to Mobilize in Difficult Situations (e.g., "I notice many solutions in difficult situations"). The respondents indicated their agreement with each item on a 5-point Likert scale (0 "I definitely disagree," 4 - "I definitely agree"). The higher the partial scores on each scale or the total score, the higher the degree of resilience.

\section{Level of stress}

The Perception of Stress Questionnaire was used to measure the intensity of subjectively perceived stress [20]. The questionnaire consists of 27 items forming 4 subscales: Emotional Tension (7 items, e.g., "I get nervous more often than I used to, and for no obvious reason"), External Stress (7 items, e.g., "I am criticized too frequently"), and Intrapsychic Stress (7 items, e.g., "Thinking about my problems makes it hard for me to fall asleep"), as well as the Lying Subscale (6 items, e.g., "I have sometimes not kept my word"). The respondents indicated their agreement with each item on a 5 -point Likert scale ( 1 - untrue, 5 - true). The higher the total score or the partial score on each of the subscales, the greater the subjective perception of stress.
The participants were also asked about their weekly workload (in hours), whether they worked in a facility, a medical team, or a quarantine facility dedicated for patients infected with COVID-19, and whether quarantine had been implemented in their workplace due to COVID-19. Due to the limitations related to the pandemic, the study was not carried out using pen-and-paper questionnaires. Instead, the authors reached out to national hospitals and nurses' associations asking them to distribute an online link to their study. Data were collected using Google forms (Google LLC, Mountain View, USA).

\section{Ethics}

This project was carried out in accordance with the recommendations of the American Psychological Association's Code of Ethics and the Declaration of Helsinki.

\section{RESULTS}

Table 1 shows the means and standard deviations of the studied variables (overwork, coping strategies, stress levels, contact with COVID-19 patients). Because coping strategies can be grouped in many different ways, the authors decided to test 3 models [15,16,21]. The most effective model, having the best fit to both the Polish and Iranian sample, was the one dividing the coping strategies into emotion-focused strategies, problem-focused strategies, and dysfunctional coping strategies.

To compare Iranian and Polish nurses in terms of the studied variables, the Mann-Whitney $U$ test was used. The results are shown in Table 2. 
Table 2. Mann-Whitney U test results for the effect of nationality on variables

\begin{tabular}{|c|c|c|c|c|}
\hline \multirow{3}{*}{ Variable } & \multicolumn{4}{|c|}{ Mann-Whitney U test } \\
\hline & \multicolumn{2}{|c|}{ nationality } & \multirow[b]{2}{*}{$\mathrm{U}$} & \multirow[b]{2}{*}{$\mathrm{p}$} \\
\hline & $\begin{array}{c}\text { Iranian } \\
(\mathrm{N}=151)\end{array}$ & $\begin{array}{c}\text { Polish } \\
(\mathrm{N}=158)\end{array}$ & & \\
\hline Overwork & 160.13 & 150.10 & 11.155 & 0.324 \\
\hline Reliance & 154.32 & 155.65 & 12.032 & 0.896 \\
\hline Problem-focused strategies & 178.31 & 132.72 & 8.409 & 0.000 \\
\hline Dysfunctional coping strategies & 175.85 & 135.07 & 8.785 & 0.000 \\
\hline Stress & 136.32 & 172.85 & 14.750 & 0.000 \\
\hline Contact with COVID-19 & 127.87 & 180.93 & 16.026 & 0.000 \\
\hline
\end{tabular}

Table 3. Mann-Whitney U test results for the effect of contact with COVID-19 on variables

\begin{tabular}{|c|c|c|c|c|}
\hline \multirow{2}{*}{ Variable } & \multicolumn{4}{|c|}{ Mann-Whitney U test } \\
\hline & $\begin{array}{c}\text { yes } \\
(\mathrm{N}=40)\end{array}$ & $\begin{array}{c}\text { no } \\
(\mathrm{N}=269)\end{array}$ & $\mathrm{U}$ & $\mathrm{p}$ \\
\hline Overwork & 114.31 & 161.05 & 7.007 & 0.002 \\
\hline Reliance & 158.05 & 154.55 & 5.258 & 0.817 \\
\hline Problem-focused strategies & 178.80 & 151.46 & 4.428 & 0.069 \\
\hline Dysfunctional coping strategies & 179.41 & 151.37 & 4.403 & 0.063 \\
\hline Stress & 120.62 & 160.11 & 6.755 & 0.009 \\
\hline
\end{tabular}

The results showed no statistically significant differences between Iranian and Polish nurses in terms of overwork and resilience. However, the groups differed in terms of utilizing various coping strategies, the levels of subjectively experienced stress, as well as the degree of contact with COVID-19 patients. Because the latter variable might be a factor differentiating the remaining variables, additional analyses were carried out. Their results are shown in Table 3.

Overwork and stress levels were statistically significant in the context of contact (or the lack thereof) with COVID-19 patients. Iranian nurses reported greater overwork and stress compared to Polish nurses.

\section{Structural model estimation}

A partial least squares (PLS) structural model with bootstrap resampling using Smart PLS software v. 3 was employed to test the relationships in the proposed model and calculate $t$-values. The results are presented in Figure 2.

The model fit for the combined data for the Iranian and Polish samples was as follows: SRMR $=0.072$,
$\mathrm{d}-\mathrm{ULS}=0.891, \mathrm{~d}-\mathrm{G}=0.128, \chi^{2}=512.727$ and $\mathrm{NFI}=0.653$. These values testify to the model's good fit to data.

A series of regression analyses were conducted to test the validity of the results obtained from the PLS method. The $\beta$ (path coefficient) and the $t$-value for each of them in the Iranian and Polish sample are shown separately in Figure 3.

As shown in Figure 3, both Iranian and Polish nurses used 4 out of 5 emotion-related coping strategies. Iranian nurses did not use humor $(\mathrm{t}=0 / 871<1 / 96)$, and Polish nurses did not rely on religion $(t=0 / 117<1.96)$. Also, both groups used 5 out of 6 dysfunctional coping strategies, with denial being the exception for Iranian nurses $(t=1 / 48<1.96)$ and self-blame for Polish nurses $(\mathrm{t}=1 / 655<1.96)$.

\section{DISCUSSION}

The obtained results show that Polish and Iranian nurses experience overwork to a similar degree (Table 2). Despite the fact that the proportion of nurses relative to the general population is greater in Poland, they often 


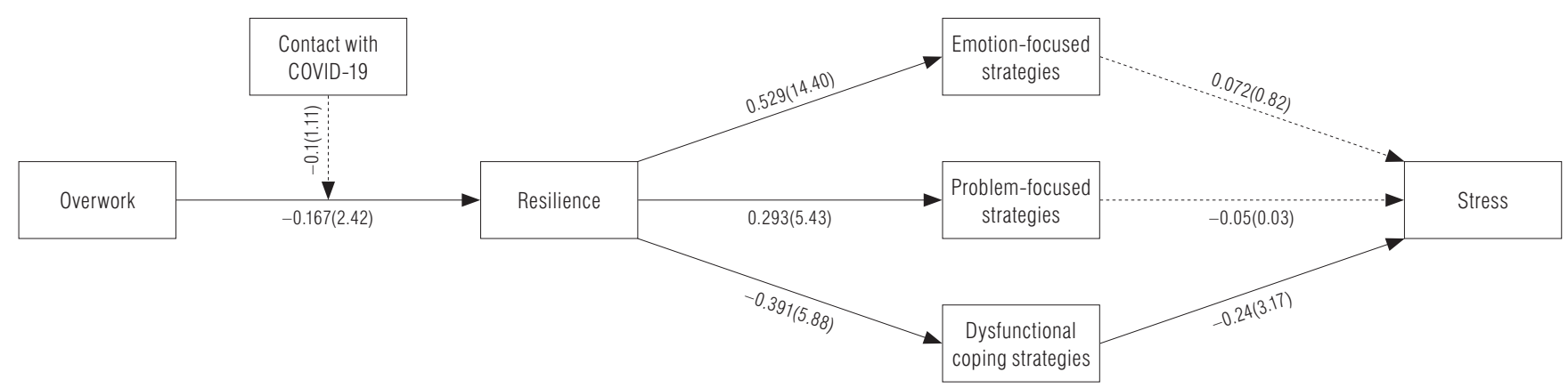

Figure 2. Results of hypothesis testing for a combined data set in the groups of Iranian and Polish nurses

work overtime, and Poland is one of the top European countries in terms of overtime hours [11]. In comparison to Polish nurses, Iranian nurses receive more support in their workplaces [22]. However, this support is not sufficient to lower their subjectively experienced stress levels to those reported by Polish nurses - the number of patients infected with COVID-19 is disproportionately greater in Iran than it is in Poland. Higher stress levels are related not only to contact with patients infected with COVID-19, but also to improper working conditions [23]. Greater anxiety and stress can, in turn, affect the quality of care the nurses are able to provide their patients with. Concerns about contracting the infection can be additionally intensified by concerns about infecting other patients.

Another variable which might affect the experience of stress is the quality of life in both countries. It can be assessed using the social progress index, in which Iran ranks 65th and Poland - 32nd [22]. Differences in the quality of life can modify the severity of everyday occurrences. Statistically, there are fewer stressful events in countries with a higher average quality of life. On the one hand, an accumulation of stressful everyday events leads to the depletion of personal resources. On the other hand, if a given person can cope with these events effectively, they improve their competence.

Iranian nurses less often declared being in contact with COVID-19 patients or working at facilities dedicated for COVID-19 patients. The obtained results are thus contrary to the official statistics released during the data acquisition period of the current study. These statistics showed that, at the beginning of July 2020, there were over 170000 patients diagnosed with COVID-19 in Iran, whereas in Poland the number of diagnosed patients was under 1500 . However, this contradiction can be spurious. First, the nurses need not have complete information about their patients' health. Second, the habituation effect might have occurred, causing the nurses to ignore the patients' infected status due to an overall high incidence rate [24]. It is also possible that the sample in the current study did not include nurses who had a high degree of contact with infected patients because of regional or institutional reasons.

During the study, Poland had reported over 140 times fewer COVID-19 infections that Iran. Iranian nurses were more burdened with work, and the pandemic additionally increased their workloads. In Poland, a small number of infections in the initial period of the pandemic gave the healthcare system more time to prepare through implementing appropriate procedures and solutions. Poland could rely on the experiences of other countries where the pandemic had developed much more rapidly, for example Italy. In Iran, nurses did not receive extra pay during the pandemic. In Poland, nurses working in units and wards dedicated for COVID-19 patients received extra pay.

Nurses exhibit high resilience, which helps them cope with stress. The results of the current study are in line with the results presented by Khanmohammadi et al. [25] who studied Iranian nurses working in wards dedicated for patients infected with COVID-19. The nurses' stress levels increased significantly during the pandemic [26]. Members of medical personnel are characterized by higher resilience compared to other professional groups $[13,18,19]$. At the same time, they experience higher levels of stress than other professions $[2,3,18]$. The confirmatory analysis (Figures 2 and 3 ) shows that overwork has not a negative effect on resilience via the moderating role of contact with patients infected with COVID-19.

Iranian nurses used emotion-focused strategies more often than Polish nurses $(M=2.933$ vs. 2.765$)$ and Polish nurses used problem-focused strategies 


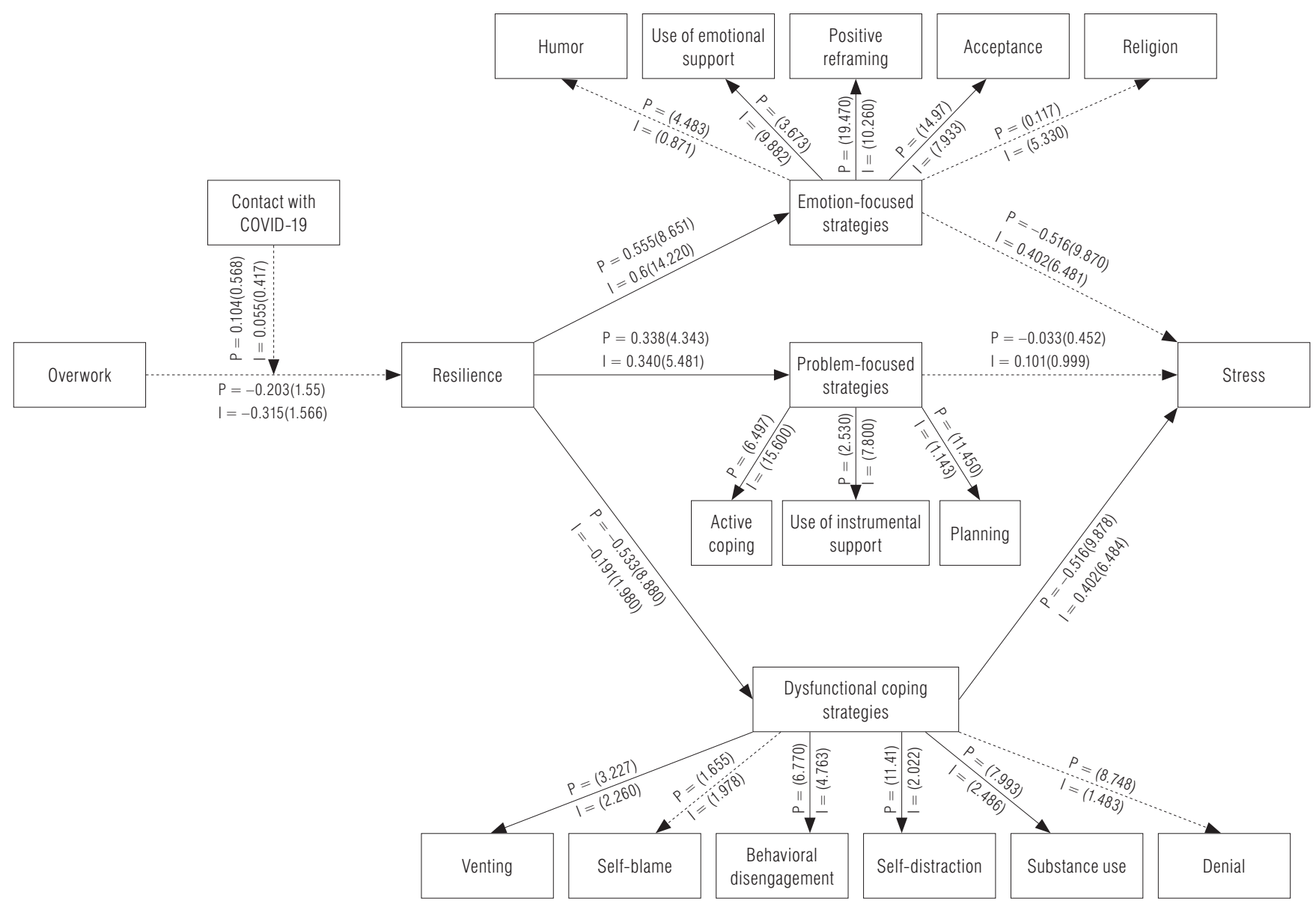

I - Iranian, P - Polish.

Figure 3. The effect of nationality on the relationships between variables in Iranian and Polish nurses

$(\mathrm{M}=3.166$ vs. 3.152$)$ and dysfunctional coping strategies $(\mathrm{M}=2.335$ vs. 2.319$)$ more often than Iranian nurses, and this differences were significant $(\mathrm{p}=0.000)$. The relationship between stress and emotion-focused strategies as well as dysfunctional coping strategies was stronger for Polish nurses. For Iranian nurses, this relationship was stronger for problem-focused strategies. Subtle differences can be observed when examining the individual coping strategies. The emotion-focused strategy of humor use was more frequent among Polish nurses, while turning towards religion was more frequent among Iranian nurses. Polish people generally use humor in social relationships more often than do Iranian people [27]. Available research shows that overwork increases the subjective experience of stress. However, in the current sample of nurses, who are rather used to overtime work, the increase in workload during the initial period of the pandemic did not deplete their resilience [11]. Using dysfunctional strategies of coping with stress increases it. This effect occurs regardless of other personal resources $[16,20,21]$.

The situational context must also be considered the intensity of the pandemic is much lower in Poland, which does not preclude humor as a dominating coping strategy. Iranian society is very religious, leading to religious coping being a common self-care behavior [28] and spiritual-religion psychotherapy being widely employed to ameliorate the consequences of stress [29]. Religion is a personal matter in Poland, whereas in Iran, people often turn to a transcendental force for support during crises. During the pandemic, religious support in Iran was provided by the servants of the Imam Reza Shrine for nurses, doctors, and patients. Among the problem-focused strategies, Iranian nurses used planning the least often, while for Polish nurses, the use of instrumental support was the least frequent. In a pandemic situation, planning can be difficult due to the necessity of rapid reactions to many new situations and challenges [30]. 
As was mentioned above, compared to Polish nurses, Iranian nurses received more support in their work [22]. Intercultural differences lead to Iranian nurses receiving both instrumental and emotional support more frequently than Polish nurses. During the pandemic, Iranian nurses met with high social support and appreciation. Low intensity of the pandemic in Poland during the data acquisition period of the current study probably did not facilitate the intense seeking of instrumental support among Polish nurses.

As regards dysfunctional coping strategies, the greatest differences can be observed for the strategies of denial, substance use, and self-distraction. Denial was not frequent among Iranian nurses. It would be extremely difficult to deny the reality and information from the media, as well as personal experience. Iranian nurses were 3 times more likely than Polish nurses to be in contact with COVID-19 patients. Long-term use of dysfunctional coping strategies leads to poorer health, a lower sense of self-efficacy, lower work effectiveness, and a lower quality of interpersonal relationships $[16,21]$.

\section{CONCLUSIONS}

In light of the obtained results, it can be concluded that Iranian nurses experience greater stress than Polish nurses. The nurses from both countries reported greater resilience when not overworked. Contact with patients infected with COVID-19 did not play a moderating role. The coping strategies used by Iranian and Polish nurses were different in terms of the chief strategies, but they showed some similarities on a general level. To reduce stress levels among nurses, it seems worthwhile to minimize overworking and to promote effective strategies of coping with stress, also taking cultural differences into account. It seems that a more intercultural study could be effective in discovering different dimensions of nursing coping strategies.

\section{Study limitations}

The current study has several limitations. First, because of the severe restrictions during the COVID-19 pandemic, the study was carried out online. Second, the study involved only 2 countries, which additionally limits the generalizability of its results. The current study only included selected organizational and psychological variables. The authors did not examine the dynamics of experiencing stress throughout the pandemic. Longitudinal studies would thus provide more data.

\section{REFERENCES}

1. Querstret D, O’Brien K, Skene DJ, Maben J. Improving fatigue risk management in healthcare: A systematic scoping review of sleep-related/fatigue-management interventions for nurses and midwives. Int J Nurs Stud. 2020;106:103513, https://doi.org/10.1016/j.ijnurstu.2019. 103513.

2. Załuski M, Jagielski P, Makara-Studzińska M. Empathy and stress: the mediating impact of the emotional labor strategies on the example of surgical nurses. Med Pr. 2020;71(4):461-471, https://doi.org/10.13075/mp.5893. 00975.

3. Janicka MJ, Basińska MA, Sołtys M. Selected personality traits of nurses and flexibility in coping with stress a moderating role of age and seniority. Med Pr. 2020;71(4): 451-459, https://doi.org/10.13075/mp.5893.00966.

4. Malinowska-Lipień I, Gabryś T, Kózka M, Gniadek A, Wadas T, Ozga E, et al. Dual practice of nurses in Poland against the current staff resources. Med Pr. 2021;72(1), https://doi.org/10.13075/mp.5893.01018.

5. Barać I, Prlić N, Plužarić J, Farčić N, Kovačević S. The mediating role of nurses' professional commitment in the relationship between core self-evaluation and job satisfaction. Int J Occup Med Environ Health 2018;31(5):649-658, https://doi.org/10.13075/ijomeh.1896.01256.

6. Sygit-Kowalkowska E. Chronic fatigue of nurses in view of the challenges of contemporary psychiatric care. Do temperament and work environment matter? Psych Pol. 2020;176:1-18, https://doi.org/10.12740/PP/OnlineFirst/ 118480.

7. Świątkowska B, Walusiak-Skorupa J, Juszczyk G, Gierczyński R, Socha K, Lipińska-Ojrzanowska A. Health protection of employees against SARS-CoV-2 coronavirus infection causing the COVID-19 disease - the current state of knowledge and recommendations. Med Pr. 2021;72(1): 69-87, https://doi.org/10.13075/mp.5893.01042.

8. McKenna H. Covid-19: Ethical issues for nurses. Int J Nurs Stud. 2020;110:103673, https://doi.org/10.1016/ j.ijnurstu.2020.103673.

9. Godlee F. Paying the ultimate price. BMJ 2020;369:m1605, https://doi.org/10.1136/bmj.m1605.

10. Mazzetti G, Schaufeli WB, Guglielmi D, Depolo M. Overwork climate scale: psychometric properties and relationships with working hard. J Manag Psychol. 2016;31(4): 880-896, https://doi.org/10.1108/JMP-03-2014-0100.

11. Piotrowski A, Jurek P. A preliminary adaptation and validation of the Overwork Climate Scale by Mazzetti, Schaufeli, Guglielmi and Depolo. Med Pr. 2019;70(2): 177-188, https://doi.org/10.13075/mp.5893.00950. 
12. Maben J, Bridges J. Covid-19: Supporting nurses' psychological and mental health. J Clin Nurs. 2020;29(15-16): 2742-2750, https://doi.org/10.1111/jocn.15307.

13. Sygit-Kowalkowska E, Szrajda J, Weber-Rajek M, Porażyński K, Ziółkowski M. Resilience as a predicator of mental health of incarcerated women. Psych Pol. 2017;51(3):549-560, https://doi.org/10.12740/PP/Online First/62617.

14. Carver CS. You want to measure coping but your protocol' too long: Consider the brief cope. Int J Behav Med. 1997;4(1):92-100, https://doi.org/10.1207/s15327558ijb m0401_6.

15. Su X, Lau JT, Mak WW, Choi K, Feng T, Chen X. A preliminary validation of the Brief COPE instrument for assessing coping strategies among people living with HIV in China. Infect Dis Poverty. 2015;4(41):1-10, https://doi. org/10.1186/s40249-015-0074-9.

16. Meyer B. Coping with Severe Mental Illness: Relations of the Brief COPE with Symptoms, Functioning, and WellBeing. J Psychopathol Behav Assess. 2001;23(4):265-277, https://doi.org/10.1023/a:1012731520781.

17. Baumstarck K, Alessandrini M, Hamidou Z, Auquier P, Leroy T, Boyer L. Assessment of coping: A new french four-factor structure of the brief COPE inventory. Health Qual Life Outcomes. 2017;15(1):1-9, https://doi.org/ 10.1186/s12955-016-0581-9.

18. Jeong JL, Kwon HM, Kim TH, Choi MR, Eun HJ. Effects of Perceived Stress, Sleep, and Depression on Resilience of Female Nurses in Rotating Shift and Daytime Fixed Work Schedules. Sleep Med Psychophysiol. 2019;26(2):111-124, https://doi.org/10.14401/KASMED.2019.26.2.111.

19. Ogińska-Bulik N, Juczyński Z. [Scale for measuring resilience (SPP-25)]. Now Psych. 2008;3:39-56. Polish.

20. Makarowski R, Plopa M. [Sense of Stress Questionnaire. Manual]. Warszawa: Vizja Press \& IT; 2010. Polish.

21. Nahlen Bose C, Bjorling G, Elfstrom M, Persson H, Saboonchi F. Assessment of Coping Strategies and Their Associations With Health Related Quality of Life in Patients With Chronic Heart Failure: the Brief COPE Restructured. Cardiol Res. 2015;6(2):239-248, https:// doi.org/10.14740/cr385w.

22. Nikkhah-Farkhani Z, Piotrowski A. Nurses' turnover intention a comparative study between Iran and Poland.
Med Pr. 2020;71(4):413-420, https://doi.org/10.13075/ mp.5893.00950.

23. Karimi Z, Fereidouni Z, Behnammoghadam M, Alimohammadi N, Mousavizadeh A, Salehi T, et al. The Lived Experience of Nurses Caring for Patients with COVID-19 in Iran: A Phenomenological Study. Risk Manag Healthc Policy 2020;13:1271-1278, https://doi.org/10.2147/RMHP. S258785.

24. McCurry KL, Frueh BC, Chiu PH, King-Casas B. Opponent Effects of Hyperarousal and Re-experiencing on Affective Habituation in Posttraumatic Stress Disorder. Biol Psychiatry Cogn Neurosci Neuroimaging 2020;5(2): 203-212, https://doi.org/10.1016/j.bpsc.2019.09.006.

25. Khanmohammadi S, Hajibeglo A, Rashidan M, Bekmaz K. Relationship of resilience with occupational stress among nurses in coronavirus ward of Khatam Al-Anbia Hospital, Gonbad Kavous, 2020. Neuropsych. Neuropsych. 2020;15(1):1-6, https://doi.org/10.5114/nan. 2020.97397.

26. Breillat R, Birtus M. Is the COVID-19 Outbreak Severely Affecting the Psychological Well-Being of Frontline Respiratory and Intensive Care Physicians and Nurses? Psychosociol Iss Human Res Manag. 2020;8(1):49-54, https://doi.org/10.22381/PIHRM8120208.

27. Schermer JA, Rogoza R, Kwiatkowska MM, Kowalski CM, Aquino S, Ardi R, et al. Humor styles across 28 countries. Curr Psychol. 2019;1-16, https://doi.org/10.1007/s12144019-00552-y.

28. Sharif Nia H, Pahlevan Sharif S, Goudarzian A, Allen K, Jamali S, Heydari Gorji MA. The Relationship between Religious Coping and Self-Care Behaviors in Iranian Medical Students. J Relig Health 2017;56(6):2109-2117, https://doi.org/10.1007/s10943-017-0376-2.

29. Ghotbabadi SS, Alizadeh KH. The Effectiveness of Spiritual-Religion Psychotherapy on Mental Distress (Depression, Anxiety and Stress) In the Elderly Living In Nursing Homes. Health Spirit Med Ethics 2018;5(1): 20-25, https://doi.org/10.29252/jhsme.5.1.20.

30. Leonardi M, Horne AW, Vincent K, Sinclair J, Sherman KA, Ciccia D, et al. Self-management strategies to consider to combat endometriosis symptoms during the COVID-19 pandemic. Hum Reprod Open 2020;(2):hoaa028, https:// doi.org/10.1093/hropen/hoaa028.

This work is available in Open Access model and licensed under a Creative Commons Attribution-NonCommercial 3.0 Poland License - http://creativecommons.org/licenses/by-nc/3.0/pl/deed.en. 